\title{
CARACTERIZAÇÃO DO ENTORNO DA RESERVA FLORESTAL EMBRAPA/EPAGRI DE CAÇADOR (SC) USANDO IMAGEM IKONOS
}

\author{
Gilberto Kurasz ${ }^{1}$, Nelson Carlos Rosot ${ }^{2}$, Yeda Maria Malheiros de Oliveira ${ }^{3}$, \\ Maria Augusta Doetzer Rosot ${ }^{3}$ \\ ${ }^{1}$ Eng. Florestal, M.Sc., Itaipu Binacional, Foz do Iguaçu, PR, Brasil - gkurasz@itaipu.gov.br \\ ${ }^{2}$ Eng. Florestal, Dr., Depto. de Ciências Florestais, UFPR, Curitiba, PR, Brasil - ncrosot@ufpr.br \\ ${ }^{3}$ Enga $^{\mathrm{a}}$. Florestal, Dra ${ }^{\mathrm{a}}$, Embrapa Florestas, Curitiba, PR, Brasil - yeda@cnpf.embrapa.br - augusta@cnpf.embrapa.br

\begin{abstract}
Resumo
A Reserva está situada numa área de grande importância econômica. A região está sob intenso processo antrópico de ocupação do solo, com a conseqüente redução da biodiversidade regional. $\mathrm{O}$ fragmento florestal - com área de 1.157,48 ha - é um dos remanescentes mais importantes e mais representativos de Floresta Ombrófila Mista. Este trabalho teve por objetivo analisar o padrão da fragmentação florestal no entorno, até $2 \mathrm{~km}$ ao redor da Reserva. Foi elaborado um mapa do uso do solo por interpretação visual, usando uma imagem Ikonos, complementado por trabalho de campo. As classes obtidas foram então usadas para executar a análise, que consistiu na aplicação de algumas métricas tradicionais de ecologia da paisagem. Constatou-se que a presença de reflorestamentos no perímetro da Reserva é estratégica para a redução do impacto do efeito da borda. Verificou-se que mais de $80 \%$ dos fragmentos do entorno possuem área menor do que 5 ha e que a forma dos maiores é bastante irregular, com uma densidade de 1,04 fragmentos/100 ha, o que indica uma fragmentação regional elevada. Seria desejável a adequação das propriedades do entorno à lei ambiental, considerando que as áreas ripárias recuperadas agiriam como os corredores naturais que conectam os fragmentos menores à Reserva.

Palavras-chave: Ecologia de paisagem; métricas; Floresta Ombrófila Mista; Floresta com Araucária.
\end{abstract}

\begin{abstract}
Characterization of the Forest Reserve Embrapa/Epagri at Caçador(SC) (Brazil) neighborhood using Ikonos image. The Reserve is located in an area of great economical importance. The region is under intense anthropogenic process, what means a possibility of regional biodiversity reduction. The forest patch has an area of 1.157,48 hectares and is one of the most representative remnants of the Mixed Ombrophilous Forest, also called Araucaria Forest. This paper objective was to analyze the pattern of the Reserve surroundings, up to $2 \mathrm{~km}$ around of the Reserve perimeter. The land use map was obtained by visual interpretation, using Ikonos imagery plus fieldwork and the typological classes were used for the landscape analysis, which consisted of some traditional landscape ecology metrics. It was evidenced that the presence of man-made forest in the perimeter of the Reserve is strategic for the impact of the edge effect the reduction. It was also verified that more than $80 \%$ of the Reserve surroundings patches are smaller than 5 hectares, and presents irregular shape. The average of 1,04 patches $/ 100$ ha indicates a high regional fragmentation. The Reserve surrounding landscape would be improved with the application of the Brazilian environmental rules to the neighborhood rural properties, considering that the riparian areas would act as natural corridors connecting small patches to the Reserve area.

Keywords: Landscape ecology; metrics; Mixed Ombrophilous Forest; Araucaria Forest.
\end{abstract}

\section{INTRODUÇÃO}

A expansão antrópica tem intensificado as pressões sobre áreas com florestas naturais que, muito freqüentemente, não resistem à rápida ampliação da fronteira agrícola e de projetos urbanos. Entretanto, também têm-se ampliado as preocupações com a qualidade de vida e o balanço entre áreas vegetadas e 
áreas intensamente povoadas (OLIVEIRA, 2000), sendo que alguns desses esforços têm sido materializados sob a forma de Unidades de Conservação (UCs). Para Viana; Pinheiro (1998), entretanto, a definição de estratégias para a conservação da biodiversidade deve ultrapassar os limites das UCs e considerar as características e potencial de conservação dos fragmentos vizinhos. Porém, um dos principais problemas enfrentados quando do estabelecimento de estratégias de proteção às UCs refere-se à falta de políticas em âmbito nacional, regional e local que permitam e visem a conexão entre áreas vegetadas, o que acaba transformando essas áreas em verdadeiras "ilhas verdes" suscetíveis às influências externas totalmente desfavoráveis à sua existência (GOMES, 2001).

A teoria do Equilíbrio da Biogeografia de Ilhas Oceânicas foi concebida por MacArthur; Wilson (1967), considerando-se que fragmentos florestais localizados em área de intensa ação antrópica assemelham-se às ilhas oceânicas, separadas dos continentes aos quais estiveram ligadas em outras épocas. O mesmo conceito tem sido bastante adotado para ambientes terrestres. Os fragmentos remanescentes, às vezes pequenos e muito alterados, estão normalmente ilhados em meio a grandes áreas agrícolas e sofrem assim forte pressão antrópica, em que as principais formas de distúrbios referem-se à extração de lenha, à extração de plantas medicinais e ornamentais, ao fogo, à invasão de espécies animais e vegetais exóticas e ao isolamento em relação a outras florestas. Como conseqüência disso, tem-se alterações profundas nas funções ecológicas dessas florestas, como a extinção local de espécies e o desequilíbrio nas taxas de reprodução e crescimento, o que afeta todas as populações, inclusive as de espécies arbustivo-arbóreas. Esses distúrbios tendem a ser mais drásticos quanto menor o fragmento e quanto maior o seu isolamento, e são mais intensos nas suas bordas (SILVA; MARTINS, 2001).

$\mathrm{O}$ entendimento das relações espaciais entre fragmentos florestais, das interações e das mudanças estruturais de uma paisagem, tem sido objeto de estudo da Ecologia da Paisagem, que analisa como os elementos de uma área ou região são configurados em relação aos outros, e como tal estrutura influencia os padrões e processos ecológicos (WIENS; MILNE, 1989).

Para Metzger (2001), a Ecologia da Paisagem é uma nova área de conhecimento dentro da ecologia, marcada pela existência de duas principais abordagens: uma geográfica, que privilegia o estudo do homem sobre a paisagem e a gestão do território; e a outra ecológica, que enfatiza a importância do contexto espacial sobre os processos ecológicos e a importância dessas relações em termos de conservação biológica. Para Forman; Godron (1986), a paisagem no âmbito geoecológico pode ser vista como um conjunto de ecossistemas que interagem em diferentes níveis hierárquicos, podendo ser resumidamente definida como um mosaico de sistemas cuja estrutura é estudada em relação a padrões espaciais de heterogeneidade. Nesse enfoque, a escala é um elemento de extrema importância para a compreensão dos geoecossistemas ou paisagens. Assim, a estrutura, a função e a dinâmica das paisagens dependerá da escala de análise (FORMAN, 1995).

Segundo $\mathrm{Wu}$ et al. (2000a), o objetivo principal da ecologia da paisagem é compreender a formação, a dinâmica e a manutenção da heterogeneidade espacial. Para eles, a heterogeneidade espacial é o fundamento mais característico de todas as paisagens, e a multiplicidade de escala é inerente à heterogeneidade. Assim, a análise multiescala é imperativa para se compreenderem a estrutura, a função e a dinâmica das paisagens.

De acordo com Narumalani et al. (2004), uma forma de analisar o grau de fragmentação da paisagem é pelo uso dos indicadores quantitativos baseados nas propriedades e no arranjo espacial de fragmentos dentro da paisagem. Comentam ainda que medidas estruturais quantitativas podem ser usadas para se analisarem testes padrões da paisagem e estudar o comportamento do tempo com as métricas.

O presente trabalho teve por objetivo mapear a paisagem no entorno da Reserva Florestal Embrapa/Epagri utilizando imagem orbital digital de alta resolução (Ikonos), de modo a caracterizar o seu estado atual como "zona tampão" para a área da Reserva, isto é, sua capacidade de atuar como amortecedor para as atividades fora da área protegida, fazendo uso da análise da paisagem. Goetz et al. (2003) destacam que as aplicações dos dados obtidos pelo uso de imagem de alta resolução podem ajudar no monitoramento e na gestão dos recursos naturais, parques e outras áreas protegidas, e também para avaliar os efeitos de desastres naturais ou para complementar medidas protetoras em áreas com potencial a queimadas ou inundações.

\section{MATERIAL E MÉTODOS}

A área onde está localizada a Reserva Embrapa/Epagri foi declarada área de utilização pública há aproximadamente 57 anos, através do Decreto $n^{\circ} 25.407$, de 30 de agosto de 1948. Essa área pertence 
formalmente à Empresa Brasileira de Pesquisa Agropecuária (EMBRAPA), mas está sob contrato de comodato junto à Empresa Catarinense de Pesquisa Agropecuária (EPAGRI) e é um dos maiores remanescentes contínuos (1.157,48 ha) com vegetação característica do bioma Floresta Ombrófila Mista (FOM). A Reserva Florestal localiza-se no município de Caçador, região centro-oeste do estado de Santa Catarina (Figura 1), situando-se entre as coordenadas geográficas $50^{\circ} 59^{\prime}$ e $50^{\circ} 53^{\prime}$ de longitude Oeste de Greenwich e de $26^{\circ} 49^{\prime}$ e $26^{\circ} 53^{\prime}$ de latitude Sul, com altitude que varia de 920 a 1.075 metros s.n.m., nos planaltos elevados do Rio Uruguai no Alto Vale do Rio do Peixe.

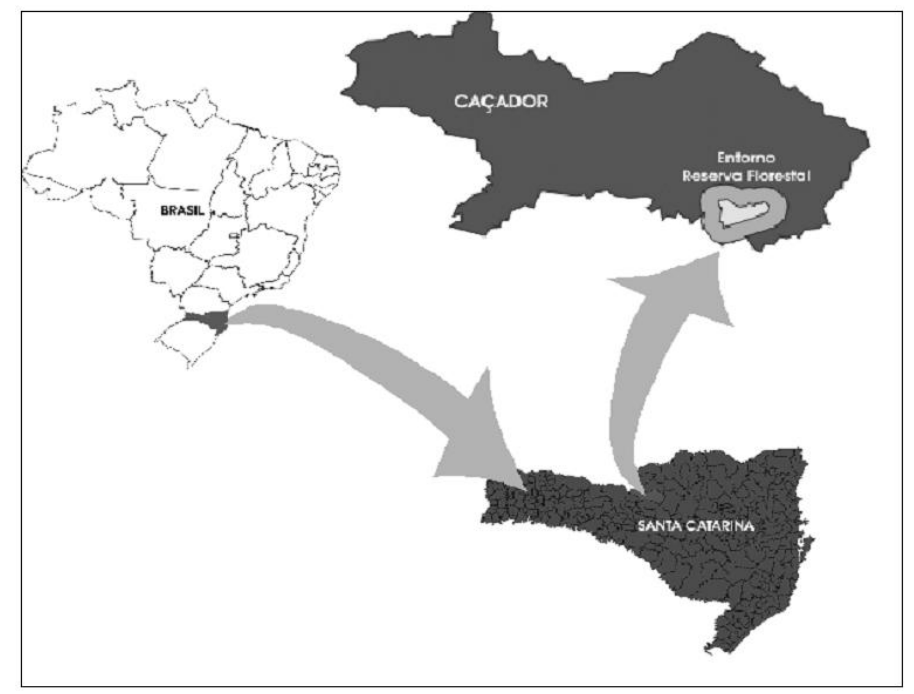

Figura 1. Localização da área de estudo.

Figure 1. The study area location.

Para a realização deste estudo, foi empregada uma imagem orbital digital do sensor Ikonos, composição colorida das bandas espectrais Near Infrared+Green+Blue (NGB), resolução espectral de 4 metros, datada de 17/02/2004, tratada no ambiente computacional do ArcView 3.2 (ESRI). Levando em consideração apenas aspectos visuais, a composição colorida NGB foi escolhida devido à maior facilidade que essa composição proporcionava para o reconhecimento, a identificação e a associação das respostas espectrais registradas pela imagem Ikonos às respectivas tipologias florestais presentes na área de estudo. Narumalani et al. (2004), em seu artigo, utilizaram uma imagem Ikonos de alta resolução para ajudar no processo de interpretação nos casos em que havia uma confusão entre as categorias da cobertura vegetal, pois conteve a informação da cor e do tonal. Inicialmente, gerou-se um buffer - zona tampão - de $2 \mathrm{~km}$ ao redor de todo o limite da Reserva em função das dimensões da subcena Ikonos.

A imagem Ikonos já apresentava correção geométrica (georreferenciamento), porém com precisão de posicionamento de $15 \mathrm{~m}$ (baixa precisão). Para aumentar a precisão, essa imagem foi submetida a um novo processo de georreferenciamento, utilizando pontos de controle coletados em campo. Para maximizar a precisão dos dados, alguns critérios foram seguidos durante a coleta com o equipamento GPS Diferencial, tais como método relativo e modo estático, tempo mínimo de 20 minutos de registro de sinais dos satélites em cada ponto, captação de sinais de quatro satélites ou mais e PDOP $\leq 6,0$. Posteriormente à coleta, os dados brutos foram submetidos a uma correção diferencial, usando-se os dados da base da Estação de Referência da Santiago \& Cintra, localizada em Curitiba-PR, distante a aproximadamente $225 \mathrm{~km}$ em linha reta do centro da área de estudo. Ao todo foram adquiridos 25 pontos de controle em campo que apresentaram precisão horizontal média de 1,33 m.

Como havia à disposição uma imagem Ikonos da fusão de bandas multiespectrais e pancromática (com resolução espacial de $1 \mathrm{~m}$ ), foram aplicados sobre essa imagem os pontos de controle para o georreferenciamento pelo método "imagem-mapa". Depois de georreferenciada, a imagem fusionada serviu de base para a correção geométrica das bandas multiespectrais (arquivo metafile) e também para a banda pancromática individual, fazendo-se georreferenciamento pelo método "imagem-imagem". A equação de transformação "polinômio de primeiro grau" e a reamostragem pelo interpolador "vizinho 
mais próximo" foram utilizadas porque este interpolador mantém os valores originais dos níveis de cinza da imagem sem gerar valores intermediários, preservando as estatísticas da imagem.

O mapa de cobertura do solo foi gerado no software ArcView e obtido por meio da interpretação visual da imagem e da poligonização das unidades de paisagem na tela do computador, considerando-se os diferentes padrões tonais, o tamanho, a forma e a textura. Utilizaram-se 5 ha como área mínima de fragmentos, em função da alta resolução da composição utilizada na imagem Ikonos e da consistência na delimitação dos polígonos, pois, segundo Narumalani et al. (2004), a interpretação de imagem é uma disciplina altamente subjetiva e requer que o analista se familiarize com a geografia e a história do uso da terra, motivo pelo qual diversas visitas devem ser realizadas. Foi também realizada a edição dos atributos referentes às categorias e tipos de cobertura (ou unidades de paisagem) ocorrentes na área de estudo.

A abstração do fenômeno vegetação visando um estudo da ecologia da paisagem exige sua discretização em unidades de paisagem (unidades básicas de trabalho), representadas por polígonos com atributos. No presente trabalho, os descritores da estrutura da paisagem foram calculados com o auxílio do software ArcView 3.2. Os índices de paisagem quantificados foram:

- Área total dos fragmentos: igual ao somatório das áreas dos fragmentos com área mínima especificada. É a medida da composição da paisagem e especifica o quanto da paisagem é composta por um tipo particular de vegetação.

- Área total da paisagem (zona tampão): compreende a região do entorno da área em estudo, definida através de um raio a partir dos limites da área em questão, no caso, $2 \mathrm{~km}$.

- Porcentagem da paisagem coberta por fragmentos: é a área percentual de vegetação encontrada, contida na área total da paisagem.

- Número de fragmentos: essa medida, juntamente com a densidade e o tamanho médio dos fragmentos, é considerada a melhor representante da configuração da paisagem. O número de fragmentos de um tipo particular de hábitat pode afetar uma variedade de processos ecológicos, dependendo do contexto da paisagem. Por exemplo, o número de fragmentos pode determinar o número de subpopulações em uma população.

- Densidade de fragmentos: é expressa pelo número médio de fragmentos por unidade de área. Permite comparações entre paisagens de tamanhos diferentes.

- Tamanho médio dos fragmentos: soma das áreas dos fragmentos, dividido pelo número de fragmentos.

- Desvio padrão: é uma medida de variação absoluta. Ela é função do tamanho do fragmento e expressa, em média, o quanto os valores observados (tamanho dos fragmentos) variam em relação à sua média (tamanho médio dos fragmentos).

- Coeficiente de variação: por causa da grande variação no tamanho dos fragmentos, esse índice é preferível em relação ao desvio padrão para se comparar a variabilidade entre paisagens. Ele mede a variabilidade relativa em relação à média e não à variabilidade absoluta. Dessa maneira, não é necessário conhecer o tamanho médio para interpretar o coeficiente de variação.

- Área interior total dos fragmentos: é a área total dos fragmentos, descontando o efeito da borda. Neste estudo, considerou-se um efeito borda de $50 \mathrm{~m}$.

- Porcentagem da paisagem coberta pela área interior dos fragmentos: esse índice expressa a área interna do fragmento depois de eliminada a área da borda em relação à área total da paisagem. Para organismos fortemente associados com o interior do fragmento, esse índice pode prover uma medição da disponibilidade do hábitat melhor que a do seu contraposto (porcentagem da paisagem coberta por fragmentos).

- Número de fragmentos com área interior: considera o número de fragmentos que, depois de descontada a borda, ainda possuem a área mínima considerada no estudo, no caso, 5 ha.

- Densidade dos fragmentos considerando sua área interior: expressa o número médio de fragmentos por unidade de área, após a retirada da área referente à borda.

- índice de circularidade ou fator de forma: relação entre a área de um fragmento e seu perímetro.

Foi adotada a forma vetorial de representação das informações referentes à cobertura do solo da paisagem estudada no Sistema de Informações Geográficas (SIG), já que a digitalização sobre a imagem foi feita com topologia arco-nó-polígono inerente ao software utilizado. Finalmente, as informações obtidas foram integradas no SIG, para a realização das análises espaciais que possibilitaram a descrição da estrutura e o padrão da paisagem do entorno da Reserva. 


\section{RESULTADOS E DISCUSSÃO}

A interpretação visual da imagem Ikonos resultou em um mapa temático (Figura 2) que reflete a forma e as relações topológicas das unidades utilizadas na análise da ecologia da paisagem, representadas por polígonos e seus atributos. A metodologia de mapeamento permitiu o delineamento de unidades de paisagem com detalhamento equivalente à escala de 1:6.000. Para este trabalho, não foi realizado o cálculo da acurácia da interpretação, uma vez que a poligonização e verificação das classes foram realizadas in loco, em paralelo às viagens de reconhecimento e coleta de dados na área de interesse (Reserva).

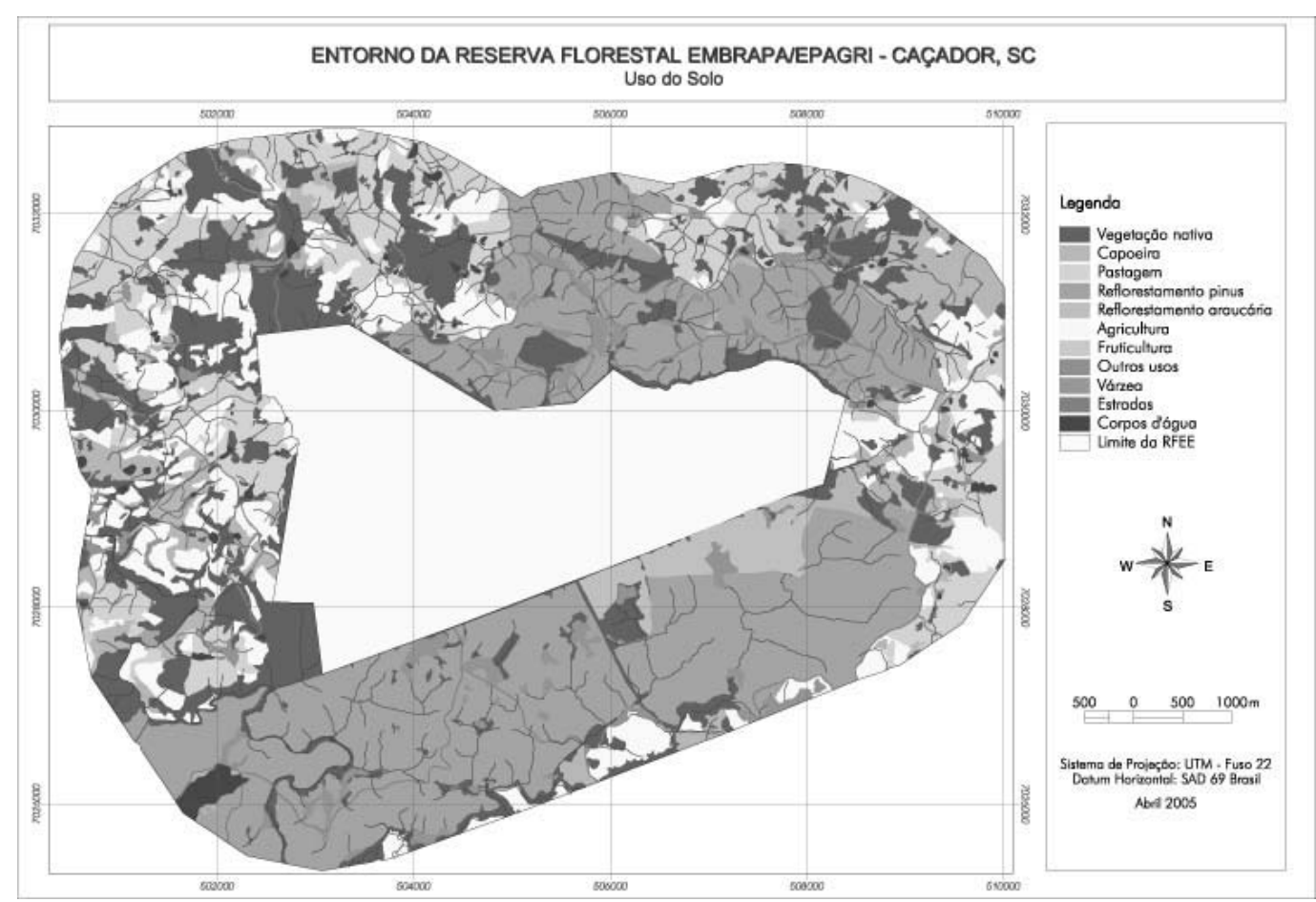

Figura 2. Mapa de uso do solo no entorno da Reserva Florestal Embrapa/Epagri de Caçador (SC). Figure 2. Neighborhood Land use Map of the Embrapa/Epagri Forest Reserve (Caçador-SC).

O uso do solo predominante no entorno da Reserva é representado pelos reflorestamentos, totalizando $37,54 \%$ de sua área (buffer de $2 \mathrm{~km}$ ), seguidos de vegetação nativa $(21,47 \%)$, conforme tabela 1 .

Tabela 1. Uso e cobertura do solo do entorno da Reserva Embrapa/Epagri.

Table 1. The Forest Reserve Embrapa/Epagri neighborhood land use and cover.

\begin{tabular}{lrrr}
\hline Classes & Área (ha) & \% & Número de polígonos \\
\hline Reflorestamentos & $1.666,19$ & 37,54 & 47 \\
Vegetação nativa & 953,01 & 21,47 & 256 \\
Agricultura & 620,27 & 13,97 & 128 \\
Pastagem & 625,21 & 14,09 & 66 \\
Capoeiras & 329,51 & 7,42 & 84 \\
Várzeas & 141,68 & 3,19 & 109 \\
Corpos d'água & 51,80 & 1,17 & 63 \\
Outros & 9,38 & 0,21 & 11 \\
Fruticultura & 4,26 & 0,10 & 3 \\
Estradas & 37,15 & 0,84 & 11 \\
\hline Total & $4.438,46$ & 100,00 & 778 \\
\hline
\end{tabular}


Como os reflorestamentos são os maiores confrontantes da Reserva, ocupando $29,53 \%$ do seu perímetro ao sul $(\sim 5093,30 \mathrm{~m})$ com Pinus (Pinus sp L.) e araucária (Araucaria angustifolia (Bertol.) Kuntze), e 30,68\% ao norte $(\sim 5290,85 \mathrm{~m})$ com Pinus sp, tais plantações florestais podem garantir o baixo fluxo de pessoas e caçadores circulando livremente pela área, uma vez que essas propriedades são particulares e possuem serviços de vigilância e segurança. Por outro lado, como são extensas áreas ocupadas por espécies exóticas que se adaptam facilmente às condições locais, é necessário o monitoramento e o controle de sua expansão através do Manejo Florestal. As atividades envolvendo reflorestamentos atenuam o efeito de borda em fragmentos florestais, diminuindo o risco de incêndios florestais, pois os proprietários adotam práticas de prevenção e combate (VIANA et al., 1998), normalmente ausentes na maior parte das propriedades agropecuárias que não possuem atividades florestais. Os reflorestamentos como zona tampão podem, portanto, representar um grande benefício para a conservação de fragmentos florestais nativos, fato também constatado por Viana; Pinheiro (1998).

Cerca de 44,21\% do perímetro sul da Reserva está ocupado com plantios de Araucaria angustifolia em estágio avançado de desenvolvimento, o que representa um ponto positivo para sua conexão com a Reserva, já que se trata de espécie nativa com sub-bosque estabelecido. Assim, pode ser considerado uma extensão de sua área, favorecendo a manutenção e a circulação da fauna existente. A classe "vegetação nativa" apresentou o maior número de fragmentos na área estudada (256), sendo que apenas $46(17,97 \%$ ) destes possuem área maior que 5 ha (Figura 3). Viana; Pinheiro (1998) mapearam fragmentos com área mínima de 4 ha. $\mathrm{O}$ presente trabalho, entretanto, considerou fragmentos com área maior ou igual a 5 ha, concordando com Ditt (2002), segundo o qual áreas menores são mais suscetíveis a erros de interpretação de imagem. Na tabela 2, são apresentados os resultados obtidos utilizando-se a ferramenta Patch Analyst do ArcView 3.2.

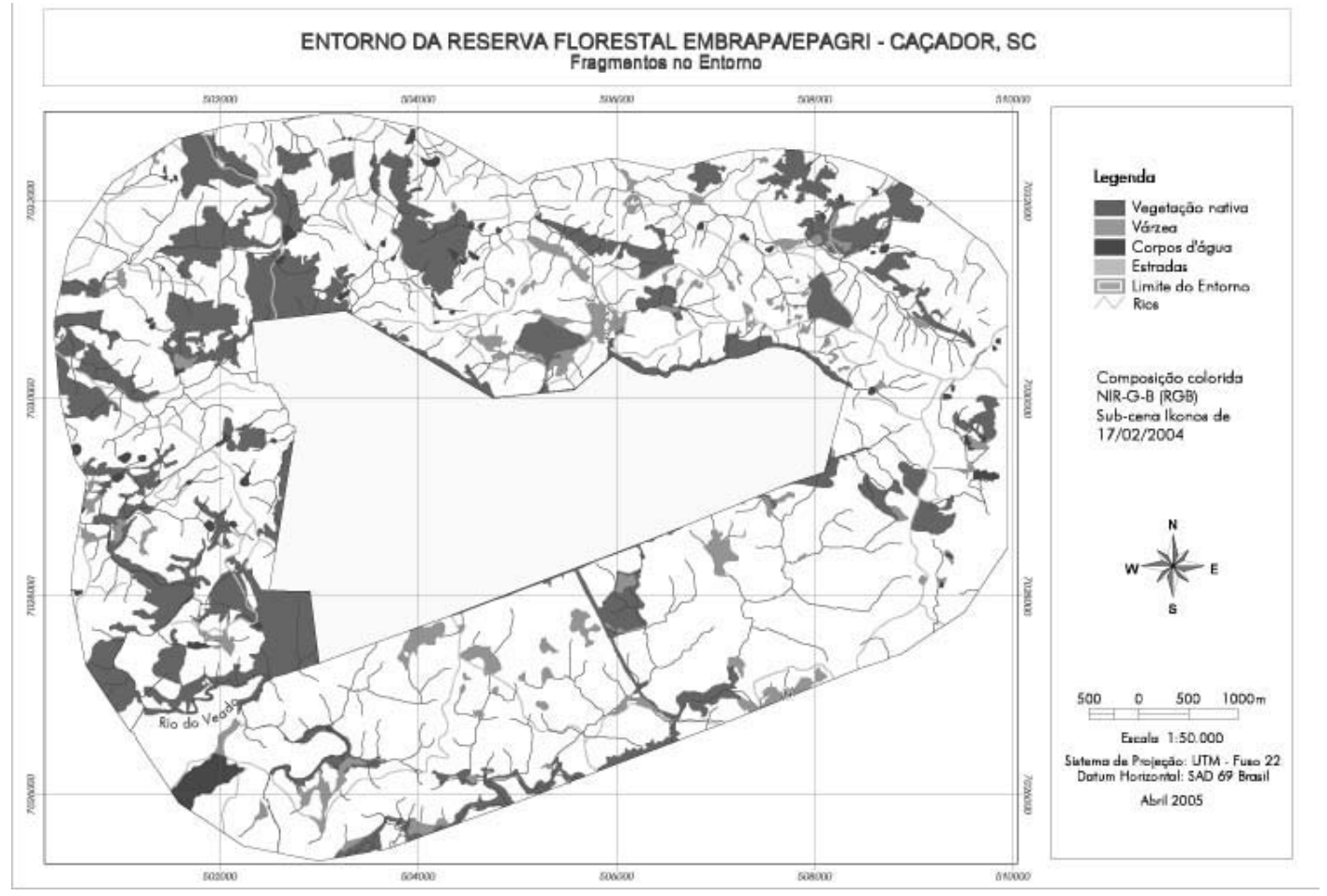

Figura 3. Fragmentos localizados no entorno da Reserva Florestal Embrapa/Epagri de Caçador (SC).

Figure 3. Patches located in the surroundings (neighborhood) of the Forest Reserve Embrapa/Epagri of Caçador (SC).

O percentual de área coberta pelos 46 fragmentos (com área $>5$ ha) estudados foi de $17,18 \%$, o que indicou a ocorrência (densidade) de 1,04 fragmentos a cada 100 ha, com um tamanho médio de 16,57 ha. O desvio padrão e o coeficiente de variação do tamanho dos 46 fragmentos com área $>5$ ha foram $\pm 12,95$ ha e $\pm 78,14 \%$, respectivamente, os quais expressam a existência de uma grande dispersão dos valores observados (área dos fragmentos) em relação à média. 
Tabela 2. Métricas de paisagem para os fragmentos florestais do entorno.

Table 2. Landscape metrics for the forest fragments of surroundings (neighborhood).

\begin{tabular}{lc} 
Métricas avaliadas & Valores encontrados \\
\hline Número de fragmentos com área $>5$ ha & 46 \\
Somatório total da área dos 46 fragmentos com área $>5$ ha & 762,31 ha \\
Área total da paisagem (buffer de 2 km ao redor da Reserva) & $4.438,46$ ha \\
Percentual da paisagem coberta por fragmentos florestais nativos & $17,18 \%$ \\
Densidade dos 46 fragmentos com área $>5$ ha & $1,04 / 100$ ha \\
Tamanho médio dos 46 fragmentos com área $>5$ ha & 16,57 ha \\
Coeficiente de variação do tamanho dos 46 fragmentos com área $>5$ ha & $\pm 78,14 \%$ \\
Desvio padrão do tamanho dos 46 fragmentos com área $>5$ ha & $\pm 12,95$ ha \\
Número de fragmentos com área de hábitat interior & 14 \\
Somatória total dos 14 fragmentos com área de hábitat interior & 176,89 ha \\
Percentual da área de hábitat interior dos 14 fragmentos & $23,20 \%$ \\
Densidade considerando área de hábitat interior dos 14 fragmentos & $0,32 / 100$ ha
\end{tabular}

O valor do índice de circularidade ou fator de forma é um parâmetro útil para a análise da vulnerabilidade dos fragmentos a perturbações, já que fornece indicativos sobre o efeito de borda (VIANA; PINHEIRO, 1998). Para os 46 fragmentos considerados, tal índice indicou que 15,22\% dos fragmentos apresentaram forma alongada ou irregular $(0,8>$ índice/fator $<0,6)$, enquanto $84,78 \%$ dos fragmentos apresentaram forma alongada bastante irregular (índice/fator $\leq 0,6$ ), que se distancia bastante do círculo. Provavelmente são unidades com maiores probabilidades de sofrer as conseqüências negativas do efeito de borda, com área de hábitat interior (área muitas vezes denominada de "core", onde há menos influência da vizinhança e ações externas) minimizada.

Com o objetivo de se investigar qual o efeito espacial da redução no tamanho dos fragmentos no contexto da paisagem local e para caracterizar melhor a análise, exercitou-se um cenário temporal bastante provável, considerando um efeito de borda que reduziria, ao longo de um futuro próximo, o tamanho de fragmentos numa razão de 50 metros a partir de sua borda. Com essa abordagem preditiva, verificou-se que apenas $31,11 \%$ dos fragmentos manteriam área de hábitat interior, ou seja, haveria uma redução de 762,31 ha para 176,89 ha, o que equivale a 23,20\% da área original dos fragmentos com mais de 5 ha. Assim, em função de uma possível ação antrópica, a diminuição no número de fragmentos existentes na área estudada poderá ser acentuada no médio/longo prazo, já que a redução seria de 46 para 14 fragmentos, ou seja, de uma densidade de 1,04 fragmentos (situação atual) para 0,32 a cada 100 hectares (hipótese analisada). Tal situação também poderá estar associada ao baixo índice de circularidade da maioria dos fragmentos e às pequenas dimensões das ilhas ecológicas, o que poderá não garantir a sua permanência na área (Figura 4).

\section{CONCLUSÕES}

A degradação de fragmentos florestais é o resultado da complexa interação entre fatores inerentes ao processo de fragmentação, como a redução de suas áreas, a maior exposição ao efeito de borda e à constante pressão antrópica, que se combinam e manifestam gerando diferentes formas de empobrecimento. $\mathrm{O}$ presente trabalho tem como foco a proteção de uma Reserva Florestal que, por seu tamanho e localização, é de grande importância como Unidade de Conservação. Dentre os vários conjuntos de métricas, foram selecionadas aquelas que envolvem as classes de tamanho dos fragmentos, sua forma e o risco de degradação, representado por um exercício que simula o efeito de borda envolvendo os fragmentos de maior tamanho na paisagem considerada, o que levou às seguintes conclusões:

- A definição de estratégias para a proteção das UCs deve considerar os fragmentos vizinhos.

- Mais de $80 \%$ dos fragmentos vizinhos à Reserva Florestal possuem menos que 5 ha.

- A zona tampão representada pelos reflorestamentos com espécies exóticas (Pinus spp.) e a espécie nativa Araucaria angustifolia constitui-se em uma das estratégias bem sucedidas para a atenuação do efeito de borda sobre a Reserva. 
- A paisagem não é homogênea, se analisados os diferentes usos do solo no entorno da Reserva, mas não apresenta um grau de isolamento preocupante, podendo-se ampliar ainda mais a conectividade entre os maiores fragmentos ao redor da Reserva pela simples obediência à legislação, que prevê matas ciliares ao longo dos cursos d'água (que podem atuar como corredores ecológicos). Sistemas agroflorestais nas áreas de reserva legal também poderiam favorecer a diminuição do isolamento entre os fragmentos florestais.

- Uma simulação visando analisar o efeito de borda pela diminuição do tamanho dos fragmentos numa razão de 50 metros a partir de seu limite exterior permitiu prever uma redução intensa no número de fragmentos existentes na área, em função da atividade antrópica.

- $\quad$ O conjunto de descritores e índices utilizados permitiu quantificar a estrutura espacial das unidades de paisagem, além de algumas relações entre eles. Os índices de Ecologia da Paisagem, em nível de classe de uso e ocupação, permitiram analisar de maneira satisfatória a estrutura florestal do entorno, assim como conhecer seu padrão de fragmentação florestal. Entretanto, outros índices e métricas disponíveis em literatura deverão ser incorporados àqueles abordados no trabalho, possibilitando uma análise mais complexa da paisagem local.

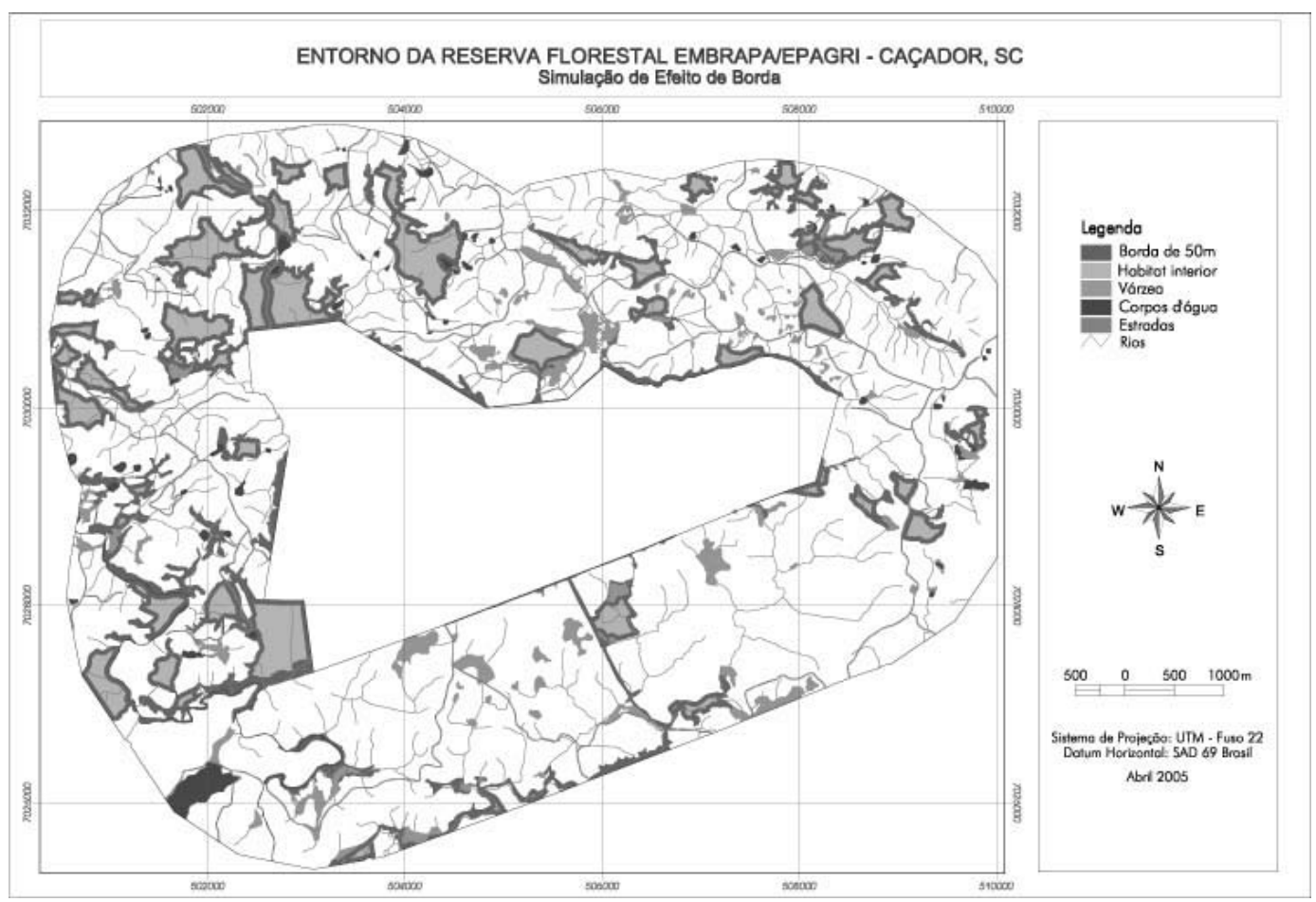

Figura 4. Fragmentos remanescentes ao efeito de borda simulado no entorno da Reserva Florestal Embrapa/Epagri de Caçador (SC).

Figure 4. Simulation of edge effect in the Forest Reserve of Embrapa/Epagri neighborhood.

\section{REFERÊNCIAS}

DITT, E. H. Fragmentos florestais no Pontal do Paranapanema. São Paulo: Annablume/Ipê/IIEB, 2002. 140 p.

FORMAN, R. T. T. Land mosaics: the ecology of landscapes and regions. [Cambridge ]: Cambridge University Press, 1995. $631 \mathrm{p}$.

FORMAN, R. T. T.; GODRON, M. Landscape ecology. New York: J.Wiley, 1986. 619 p. 
GOMES, L. J.; CARMO, M. S. do, SANTOS, R. F. dos. Conflitos entre a conservação e o uso da terra no entorno do Parque Nacional da Serra da Bocaina. 2001. Disponível em: $<$ http://mutuando.com.br/EncontroInternacional/Resumo dos Trabalhos.html >. Acesso em: 01/09/2004.

MACARTHUr, R. H.; WILSON, E. O. The theory of island biogeography. Princeton: Princeton University Press, 1967, 203 p.

METZGER, J. P. O que é ecologia de paisagens? Biota Neotrópica, São Paulo, v. 1, n. 1 e 2, 2001.

NARUMALANI, S., MISHRA, D. R., ROTHWELL, R.G. Change detection and landscape metrics for inferring anthropogenic processes in the greater EFMO area. Remote Sensing of Environment, New York, v. 91, n. 3-4, p. 478-489,2004.

OLIVEIRA, Y. M. M. de. Investigation of remote sensing for assessing and monitoring the araucaria forest of Brazil. 247 p. Tese (DPhil) - University of Oxford, Oxford, UK, 2000.

SILVA, N. R. S.; MARTINS, S. V. Considerações sobre conservação e restauração de fragmentos florestais. Folha Florestal, Viçosa, MG, n. 99, p. 7-8, 2001.

VIANA, V. M.; PINHEIRO, L. A. F. V. Conservação da biodiversidade em fragmentos florestais. Série Técnica IPEF, Piracicaba, v. 12, n. 32, p. 25-42, 1998.

WIENS, J. A.; MILNE, B. T. Scaling of 'landscapes' in landscape ecology from a beetle's perpective. Landscape Ecology, Dordrecht, v. 3, n. 2, p. 87-96, 1989. 